\title{
Analysis of Enterprise's XBRL Technology Adoption Based on Evolutionary Game Theory
}

\author{
Yong Xue, Ding Pan \\ School of Management, Jinan University, Guangzhou, China \\ Email: xyloyjk@foxmail.com
}

How to cite this paper: Xue, Y. and Pan, D. (2018) Analysis of Enterprise's XBRL Technology Adoption Based on Evolutionary Game Theory. Modern Economy, 9, 1998-2011.

https://doi.org/10.4236/me.2018.912125

Received: October 22, 2018

Accepted: December 1, 2018

Published: December 4, 2018

Copyright (C) 2018 by authors and Scientific Research Publishing Inc. This work is licensed under the Creative Commons Attribution International License (CC BY 4.0).

http://creativecommons.org/licenses/by/4.0/

(c) (i) Open Access

\begin{abstract}
Starting from the assumption of bounded rationality in game, this article explores the evolution of XBRL adoption by enterprise to enterprise, and enterprises to Government from the perspective of evolutionary game. Research shows that without government guidance, enterprise adopting XBRL technology is affected by the adoption probability of relevant enterprises or industries. In the case of government guidance, the initial state of adoption of XBRL technology by the government and enterprises affects the evolution direction and speed of the system. System evolution has obvious "path dependence". After a long period of repeated game XBRL technology adoption may be "unhealthy cycle" trend development. The results of the game have been found that influencing factors which are the probability of government mandatory adoption and the deep-seated factors that affect the adoption of XBRL technology in enterprises, for the government and business decision-making provide a reference from evolutionary direction and evolutionary stabilization strategy.
\end{abstract}

\section{Keywords}

XBRL Technology, Evolutionary Game, Government Policy, Information

\section{Introduction}

Currently, more and more countries choose the financial reporting model based on XBRL (Extensible Business Reporting Language) as the form of accounting information announcement. XBRL is an information technology based on Web financial reporting. It is an Internet-based development standard and it is also an XML-based technology innovation. It can be used to simplify the preparation, exchange and release of financial information between different computer platforms, software applications and accounting standards to improve the efficiency 
of data exchange in various fields. In China, the United States, Canada, and Europe, all financial entities and companies that quote on the stock market must enforce XBRL standards to report to regulators. Although mandatory use of $\mathrm{XBRL}$ standards is reported in these countries, the adoption and implementation of XBRL as a separate process is not within the scope of mandatory adoption [1]. Therefore, whether XBRL technology should be forced to be adopted and how the government's guiding policies will affect the development of the entire XBRL technology are scientific issues worth studying.

As a company that is one of the key stakeholders adopted by XBRL technology, XBRL brings new technology advantages while having technical complexity and implementation costs. Pinsker and Li [2] interviewed four business managers involved in XBRL procurement in Canada, Germany, South Africa and the United States. The results show that using XBRL to improve efficiency, reduce operating costs and increase transparency is an important goal of implementation. Regarding the advantages brought by XBRL adoption, Liu Chun hui et al. [3] found that the adoption of XBRL by European non-financial companies has significantly increased market liquidity and reduced information asymmetry. Chong et al. [4] analyzed the use of 554 US bank loan contract samples and found that XBRL technology advancement will reduce bank loan costs by reducing information asymmetry between borrowers and lenders. Vasilyeva [5] and others believe that XBRL technology is a typical innovation of the reporting process of the transformation enterprise in the new model, and provides a technical basis for continuous auditing of real-time reports. Lai et al. [6] found the relationship between debt cost and XBRL and found that the voluntary and mandatory adoption of XBRL led to a reduction in corporate debt costs, and recommended that XBRL be enforced for all public companies to encourage senior management to develop their company's XBRL system. Although some studies have confirmed the implementation effect of XBRL technology adoption, Santarem Segundo and Manzoni et al. [7] pointed out that some business people believe that XBRL increases the cost of information disclosure and has no impact on investment decisions, and it brings about internal correlation. The cost of technology and systems is obvious, resulting in a low level of awareness and adoption of XBRL, and there are very few real implementations of XBRL technology within the enterprise. Coincidentally, Cordery et al. [8] found that companies are not only worried that XBRL technology is too complicated to master their reporting procedures, and that implementing XBRL technology internally will replace or modify existing information systems, resulting in overly complex compatibility issues. XBRL technology is not considered to help internal management or enhance corporate value. According to transaction cost theory, the uncertainty of unverified technology increases transaction costs and capital costs during early adoption, and a key factor affecting the internal promotion of XBRL technology is the need to ensure the effectiveness of XBRL technology. This is an unavoidable problem in the adoption of XBRL technology, and it is one of the reasons why the adoption of XBRL technology in the world is slow. 
As a government that is one of the main drivers of XBRL technology adoption, XBRL, based on the concept of sustainability, can not only improve the accountability and transparency of business and financial information, but also readability and interoperability. Improve the efficiency of public information dissemination and analysis [9]. These advantages not only enable governments and public organizations to effectively manage and analyze data, but also improve regulatory capacity and quality. Therefore, the context in which XBRL technology is adopted is inextricably linked to government or regulatory agency policies such as mandatory XBRL and voluntary XBRL policies. Valentinetti et al. [10] found that government and regulatory agency policies play an important role in accelerating XBRL adoption. Liu et al. [11] confirmed through empirical research that China has found XBRL cost-cutting benefits in the early stage of XBRL adoption, which provides useful information for regulators to consider mandatory use of XBRL. Bharosa [12] pointed out that "business-to-government information exchange is the next frontier to reduce government spending while improving performance", which indicates that the improvement of government efficiency is also the driving force for the development of XBRL. However, many governments or regulators are not aware of their importance. Dunne [13] believes that if the government does not create "the driving force for XBRL for XBRL, such as creating tools and publicly acquiring XBRL databases", they fear that XBRL may "disappear". Hoffman [14] pointed out that governments, including regulators and suppliers, must be aware of the need to provide economically meaningful and secure scalable and auditable and understandable XBRL solutions. This is where the government should enforce XBRL technology and how to properly guide it. In the game analysis of XBRL, Zhao Xian ming and Zhang Tian xi [15] used the two-stage Stark berg game model to study the spread of XBRL among stakeholders and found that stakeholders using the XBRL standard were The transaction price, the number of transactions and the final profit are better than those not used. Wu Zhong sheng and Liu Qin [16] analyzed the motivation and adoption efficiency of XBRL technology in the competitive environment by establishing a competitive game model. The conclusion is whether the company adopts XBRL technology and when it adopts its competitive characteristics; the impact of other corporate decisions.

The existing research on XBRL technology rarely involves the direction of evolutionary game. In reality, the limited rationality of stakeholders determines that XBRL technology adoption is more in line with the actual situation from the perspective of evolutionary analysis. Therefore, this paper aims to analyze the game behavior and evolution path of the "limited rationality" stakeholders in the competitive environment for adopting XBRL technology. Based on this, the corresponding theoretical explanations for the development status of XBRL are given. It focuses on how the government can use the market mechanism to solve the problem of insufficient adoption and development of XBRL technology in an appropriate period of time. Finally, policy recommendations were made for the promotion of XBRL technology. 


\section{Game Analysis of Enterprise XBRL Technology Adoption}

\subsection{Basic Assumption}

This paper constructs a dynamic game model based on the frog-sounding model. The only participants involved are Enterprise A and Enterprise B. It is assumed that there are only two companies in a certain industry. If they do not adopt XBRL technology, the number of investors will be attracted. 0 investors here are new investors if one party adopts XBRL technology as a tool for information disclosure, so that investors can invest more confidently, it is assumed that they will attract 1 or $\mathrm{N}$ investors to attract Investors will still refer to the two companies. At this time, the enterprises that adopt XBRL technology have the opportunity to obtain investment $(M<0.5<M<1$, the investment probability of general investors is 0.5 ), but the adoption of XBRL technology has cost $C$, if at the same time adopting XBRL technology, the investment opportunities that each can attract are $P(M<P<1$, and the investors are assured that the investment opportunities must be greater than the investment opportunities when only one adopts). At this time, the adoption cost is also $C$. The two companies constitute the game represented by Table 1 benefit matrix.

\subsection{Construct and Analyze Game Models}

Since the above game relationship is a $2 \times 2$ symmetric game, the copy dynamic equation can be obtained directly according to the general formula.

$$
\frac{\mathrm{dx}}{\mathrm{dt}}=x(1-x)[x(P-C-1+M)+(1-x)(M-C)]
$$

Assuming that the probability of adopting XBRL technology is $X$, according to the above-mentioned replication dynamic equation, it is not difficult to find three fixed points, $x 1=0, x 2=1, x 3=(M-C) /(1-P)$.

When $0<x 3<1$ it is not difficult to see that only $\mathrm{D}$ is a stable strategy and replicates the phase diagram of the dynamic equation, as shown in Figure 1 (The abscissa: The probability that companies will adopt XBRL technology; The ordinate: The value of the dynamic equation).

In fact, this means that if the above-mentioned environmental conditions determine whether the company's adoption or non-XBRL interest relationship is stable, then once a small number of enterprises have adopted the transition from adoption to adoption, the change will continue to increase until the account. The proportion of the whole industry is $x 3$. If the proportion of enterprises adopting XBRL technology exceeds this level in the industry, and even adopt it all at once, there will be some free-riding phenomenon of enterprises that do not adopt XBRL technology. At this time, they are invested. Opportunities and interests are particularly large, and in turn will cause new changes, that is, constantly giving up the adoption of XBRL, and eventually this ratio will still return to the equilibrium ratio of $x 3$.

When $x 3<0$, the fixed point only $x 1=0, x 2=1$ meets the requirements. Copy the phase diagram of the dynamic equation as shown in Figure 2 (The 
Table 1. Game between adopting XBRL technology among enterprises.

\begin{tabular}{cccc}
\hline & \multicolumn{2}{c}{ Enterprise B } \\
\cline { 3 - 4 } & & Adopt XBRL technology & $\begin{array}{c}\text { Not adopt XBRL } \\
\text { technology }\end{array}$ \\
\hline \multirow{2}{*}{ Enterprise A } & Adopt XBRL technology & $P-C, P-C$ & $M-C, 1-M$ \\
& Not adopt XBRL technology & $1-M, M-C$ & 0,0 \\
\hline
\end{tabular}

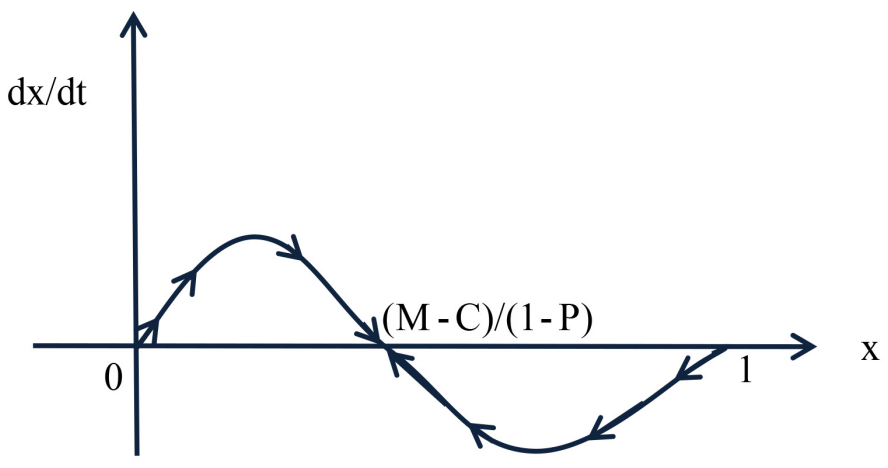

Figure 1 . When $0<x 3<1$, copy the phase diagram of the dynamic equation.

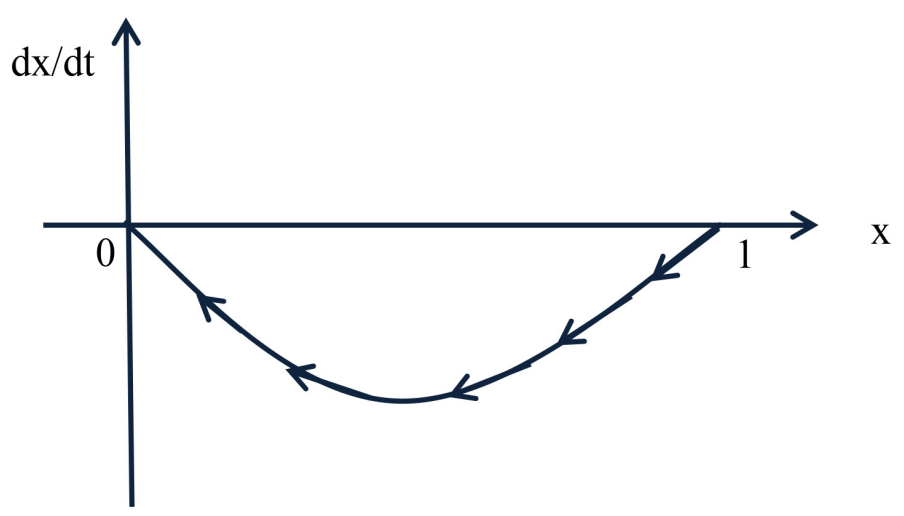

Figure 2. When $x 3<0$, copy the phase diagram of the dynamic equation.

abscissa: The probability that companies will adopt XBRL technology, The ordinate: The value of the dynamic equation).

As can be seen from the above figure, if in this case, the only equilibrium point is $x 1$, that is, all companies are not adopted. According to the reality, if all enterprises do not adopt it, even if there are a small number of adopted enterprises, they will disappear quickly. This is why the government needs certain mandatory measures to guide enterprises to adopt XBRL technology instead of relying solely on it.

When $x 3>1$, the fixed point only $x 1=0, x 2=1$ meets the requirements. Copy the phase diagram of the dynamic equation as shown in Figure 3 (The abscissa: The probability that companies will adopt XBRL technology; The ordinate: The value of the dynamic equation). 


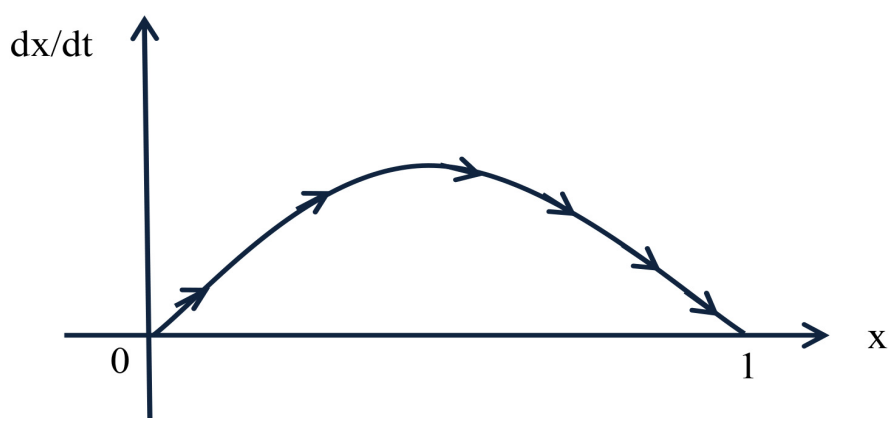

Figure 3. When $x 3>1$, copy the phase diagram of the dynamic equation.

According to the phase diagram, the current adoption strategy is that all companies adopt XBRL. This situation is of course in the very good period of XBRL development. The benefits of adoption are far greater than the cost. At this time, the government's mandatory adoption is unnecessary and can save government expenditure.

According to the analysis of the above three cases, the game of bounded rationality can not achieve the result of maximizing profit by copying dynamic learning and strategy adjustment, and it is often the second best result in the game. Therefore, when a company adopts XBRL technology, the adoption of one company and the ideal result adopted by the other company may not be realized. For economic development and to meet the needs of international development, the mandatory adoption strategies of governments and international organizations are crucial.

\section{Game Analysis of Government and Enterprise Adopting XBRL Technology}

\subsection{Basic Assumption}

The participants in the game are only two stakeholders, the government and the enterprise, and the participants in the game are bounded and rational. The goal of the enterprise is to pursue the maximization of the company's own interests; the government as a state's rights institution considers the long-term and sustainable development of society and represents the interests of the whole society. At the same time, there is no collusion between the game participants in the hypothesis. The company's pure strategy is divided into adopting XBRL technology and not adopting XBRL technology (referred to as adoption; not adopted); the government's pure strategy is divided into compulsory enterprise adoption of XBRL and non-enforcement of enterprise adoption of XBRL (referred to as mandatory, not mandatory). The meaning of the symbolic representation in the game analysis of government and enterprises is shown in Table 2.

\subsection{Construct and Analyze Game Models}

According to the establishment of the hypothesis, we can know that this is a $2 \times$ 2 asymmetric repeated game. Both the government and the enterprise can 
Table 2. Description of basic symbols of the game.

\begin{tabular}{cl}
\hline Symbol & \multicolumn{1}{c}{ Meaning (value range) } \\
\hline$x$ & Probability of government mandatory adoption of XBRL technology $(0-1)$ \\
$y$ & Indicates the probability of a company adopting XBRL technology $(0-1)$ \\
$S$ & Increased external benefits for companies after adopting XBRL technology $(S>0)$ \\
$R$ & Benefits of adopting XBRL technology $(R>0)$ \\
$C$ & The cost of adopting XBRL technology $(C>0)$ \\
$G$ & The cost of government-enforced companies adopting XBRL technology $(F>G)$ \\
$F$ & When the government imposes XBRL technology, the measures taken to punish the \\
\hline & losses that are not adopted by the enterprise are collectively called fines $(F>0)$
\end{tabular}

independently choose their own strategies. The payment matrix of both parties is shown in Table 3.

According to the above payment matrix, the government selection result in the game 1 position expects the income $U_{1 e}, U_{1 d}$ and the group average income $\bar{U}_{1}$. As follows

$$
\begin{aligned}
& U_{1 e}=y *(S-G)+(1-y)(F-G) \\
& U_{1 d}=y * S \\
& \bar{U}_{1}=x * U 1+(1-x) * U 2=F x-G x-F y x+y S
\end{aligned}
$$

The expected return of the company selection result in the game 2 position $U_{2 e}, U_{2 d}$ and the group average income $\bar{U}_{2}$. As follows

$$
\begin{aligned}
& U_{2 e}=x(R-G)+(1-x)(R-C) \\
& U_{2 d}=-F x \\
& \bar{U}_{2}=y U 1+(1-y) U 2=y R-y C+F x y-F x
\end{aligned}
$$

According to Formulas (1) and (2), the replication dynamic equations of government and enterprises can be obtained in categories:

$$
\begin{gathered}
F(x)=\frac{\mathrm{d} x}{\mathrm{~d} t}=x\left(U_{1 e}-\bar{U}_{1}\right)=x(1-x)(F-G-F y) \\
F(y)=\frac{\mathrm{dy}}{\mathrm{d} t}=x\left(U_{2 e}-\bar{U}_{2}\right)=y(1-y)(R-C+F x)
\end{gathered}
$$

According to the dynamic Equation (3), when $y=(F-G) / F$, then $\mathrm{d} x / \mathrm{d} t$ $=0$. This means that all levels are steady, if $y \neq(F-G) / F, x^{*}=0$ and $x^{*}=1$, are two stable states. When $y>(F-G) / F, x^{*}=0$ is ESS,

$y<(F-G) / F, \quad x^{*}=1$ is ESS. Figure 4 shows the trend of dynamic changes in $X$. When the probability of adoption by the company is lower than $(F-G) / F$, the government will tend to adopt the strategy, and vice versa will prefer not to enforce the strategy (The abscissa: The probability that the government will force companies to adopt XBRL; The ordinate: The value of the dynamic equation).

Analysis of the dynamic equation of replication in the game party 2, the corporate group. According to the dynamic Equation (4), when $x=(C-R) / F$, 
Table 3. Game payment matrix of government and enterprise.

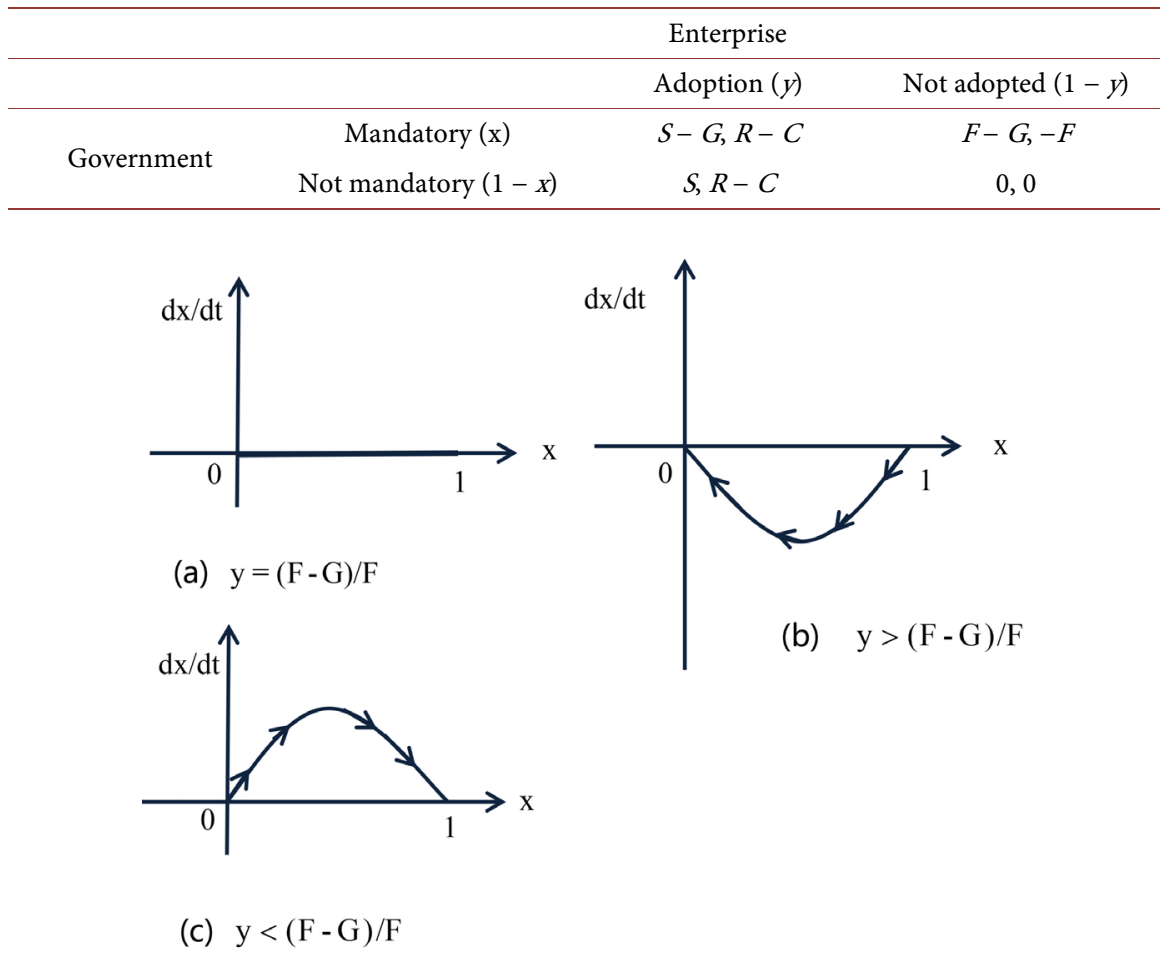

Figure 4. Government's copy dynamic phase diagram.

$\mathrm{d} y / \mathrm{d} t$ is always equal to 0 , this means that all $y$ are stable; when $x \neq(C-R) / F$, it is divided into the following situations.

Condition (1): if $C-R>0$ and $C-R<F$, then $y^{*}=0$ and $y^{*}=1$ are two stable states. when $x>(C-R) / F, y^{*}=1$ is the evolutionary stability strategy (ESS); when $x<(C-R) / F, y^{*}=0$ is the evolutionary stability strategy (ESS). The dynamic trend of y in Condition (1) is given in Figure 5.

Condition (2): if $C-R>0$ and $C-R>F$, there must be always $x<(C-R) / F$, then $y^{*}=0$ is the evolutionary stability strategy (ESS), the dynamic trend of $y$ in Condition (2) is given in Figure 6.

Condition (3): if $C-R<0, F>0>C-R$, then $x>(C-R) / F$, then $y^{*}=1$ is the evolutionary stability strategy (ESS), the dynamic trend of $y$ in Condition (3) is given in Figure 7 (The abscissa: The probability that companies will adopt XBRL technology; The ordinate: The value of the dynamic equation).

\subsection{Stability Analysis of Evolutionary Dynamics}

Conditional (1) replication dynamic system has 5 equilibrium points: $(0,1),(1,0)$, $(0,0),(1,1),((C-R) / F,(F-G) / F)$; Conditional (2) (3) replication dynamic system has 4 equilibrium points: $(0,1),(1,0),(0,0),(1,1)$. According to the research method proposed by Friedman, the stability of the equilibrium point can be obtained from the local stability analysis of the Jacobian matrix of the system. The local stability of these equilibrium points is studied below. The Jacobian matrix of the dynamic system is: 


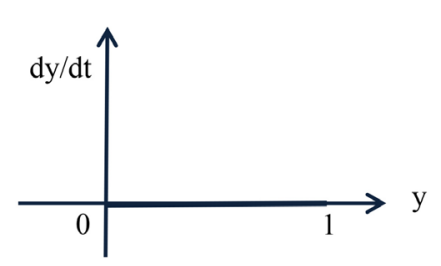

(a) $x=(C-R) / F$

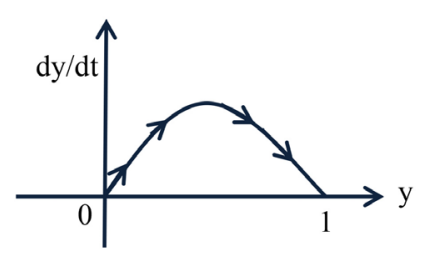

(c) $\mathrm{x}>(\mathrm{C}-\mathrm{R}) / \mathrm{F}$

Figure 5. Copying dynamic phase diagram of the enterprise.

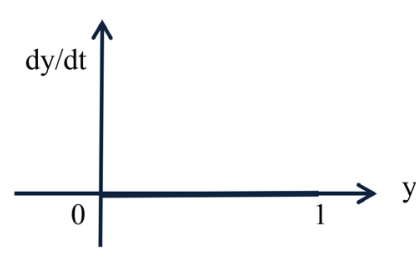

(a) $\mathrm{x}=(\mathrm{C}-\mathrm{R}) / \mathrm{F}$

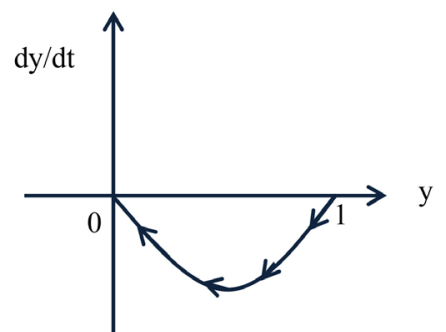

(b) $\quad x \neq(C-R) / F$

Figure 6. Copying dynamic phase diagram of the enterprise.

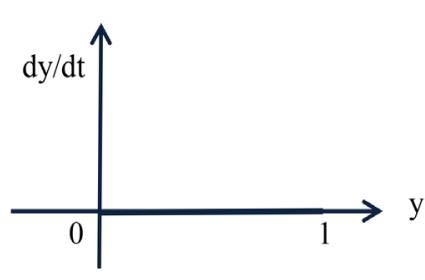

(a) $\mathrm{x}=(\mathrm{C}-\mathrm{R}) / \mathrm{F}$

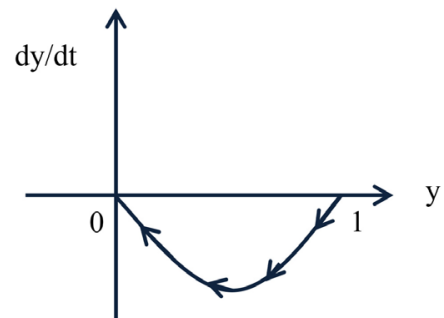

(b) $x<(C-R) / F$

Figure 7. Copying dynamic phase diagram of the enterprise.

$$
\begin{gathered}
J n=\left[\begin{array}{ll}
(1-2 x)(F-G-F y) & (-F) x(1-x) \\
y(1-y)(F) & (1-2 y)(R-C+F x)
\end{array}\right] \\
\operatorname{det} J n=(1-2 x)(F-G-F y)(1-2 y)(R-C+F x)+F^{2} x y(1-x)(1-y) \\
\operatorname{tr} J n=(1-2 x)(F-G-F y)+(1-2 y)(R-C+F x)
\end{gathered}
$$

The results of the local stability analysis can be derived from the determinant of the matrix and the trace of the matrix. The results are shown in Table 4.

According to the results of the local stability analysis of the Jacobian matrix, the equilibrium point is verified to have two equilibrium points which are stable 
Table 4. Results of local stability analysis of Jacobian matrix. $A: C-R>0$ and $C-R<F, B: C-R>0$ and $C-R>F, C: C-R<0$.

\begin{tabular}{|c|c|c|c|c|c|c|c|c|c|c|c|}
\hline \multirow{2}{*}{$\begin{array}{l}\text { Equilibrium } \\
\text { point }\end{array}$} & \multicolumn{3}{|l|}{$\begin{array}{c}\text { Jacobian matrix } \\
\text { determinant (symbol) }\end{array}$} & \multicolumn{5}{|c|}{ Jacobian matrix trace (symbol) } & \multicolumn{3}{|c|}{ Analysis result } \\
\hline & Matrix determinant & $A$ & $B$ & $C$ & matrix trace & $A$ & $B$ & $C$ & $A$ & $B$ & $C$ \\
\hline$(0,0)$ & $(F-G)(R-C)$ & - & - & + & $F-G+R-C$ & Not clear & - & + & Unstable & Saddle point & Unstable \\
\hline$(0,1)$ & $G(R-C)$ & - & - & + & $-G-(R-C)$ & Not clear & + & - & Unstable & Saddle point & ESS \\
\hline$(1,0)$ & $-(F-G)(R-C+F)$ & - & + & - & $G+R-C$ & Not clear & - & + & Unstable & ESS & Saddle point \\
\hline$(1,1)$ & $-G(R-C+F)$ & - & + & - & $G-R+C-F$ & Not clear & + & - & Unstable & Unstable & Saddle point \\
\hline $\begin{array}{l}((C-R) / F \\
(F-G) / F)\end{array}$ & {$[G(F-C+R)(C-R)(F-G)] / F^{2}$} & + & - & - & 0 & 0 & - & - & Saddle point & - & - \\
\hline
\end{tabular}

D2 $(1,0)$ and D3 $(0,1)$. D2 said (the government mandatory XBRL, the company does not adopt XBRL), D3 said (the government does not enforce XBRL, the company adopts XBRL), D5 $((R-C) / F,(F-G) / F)$ is, Saddle point.

The connection of these three points is the critical point at which the system converges to different strategies. Based on these critical points, we can draw a copy dynamic phase diagram between the government and the enterprise adopting XBRL technology, as shown in Figure 8 (The abscissa: The probability that the government will force enterprises to adopt XBRL technology; The probability that companies will adopt XBRL technology).

Regions D1, D5, D4, and D2 converge on the government's mandatory adoption of XBRL technology, and companies do not adopt the strategic combination of XBRL technology. The regions D1, D5, D4, and D3 converge on the adoption of XBRL technology by the enterprise. The government does not mandate the adoption of the XBRL technology strategy. From the perspective of sustainable development, the adoption of XBRL technology by the enterprise is conducive to the development of new technologies throughout the industry. It is better for the government to better supervise and adopt a guiding strategy, that is, to move the D5 to the upper left corner as much as possible.

\subsection{Evolution Analysis and Summary}

When $C-R>0$, that is, when the technology cost of adopting XBRL is greater than the income, at this time, the key factor affecting whether the company adopts XBRL technology is the government's policy choice. If the government's guiding strategy is not to adopt XBRL technology, Enterprises are choosing not to adopt XBRL $(0,0)$ which is in line with XBRL as a new language and new technology, and governments and companies adopt the initial state of XBRL technology. If the government-led strategy is mandatory adoption, when $C-R<F$, Enterprises will adopt adoption strategies $(1,1)$. When the cost is lower than the profit, the government's mandatory adoption probability will rise, and the adoption probability will increase. When the saddle point D5 $((R-C) / F,(F-G) / F)$ is stable, the probability that the policy will be enforced at this time is $(R-C) / F$. When $C-R>F$, At this time, the company will adopt the principle of maximizing profits and choose to abandon the adoption 


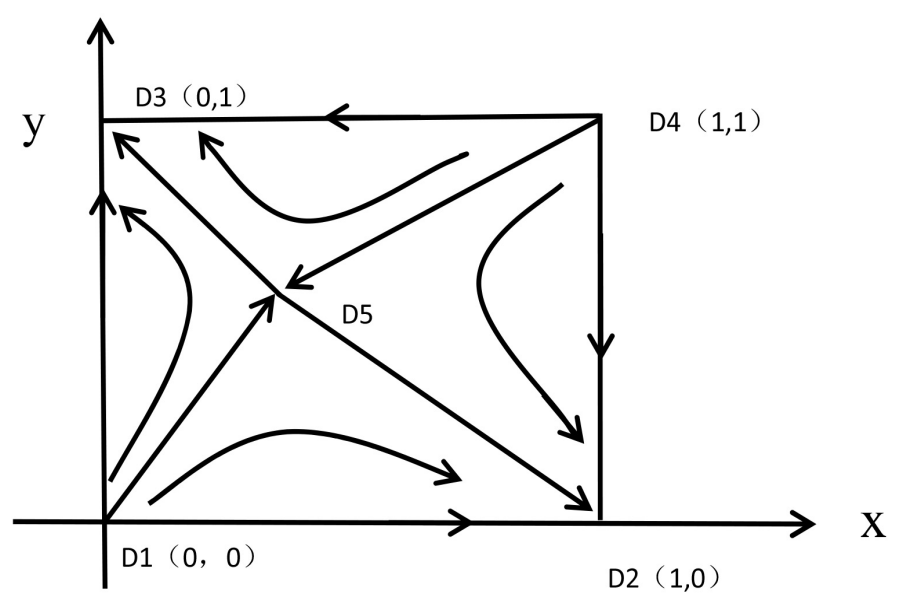

Figure 8. Dynamic phase diagram of government and business games.

of XBRL technology. Even if the government is in the stage of mandatory adoption, the equilibrium point is stable at $\mathrm{D} 2(1,0)$. When $C-R<0$, the technology cost of adopting XBRL is less than the income. If the enterprise sees the economic benefits of adopting XBRL technology, it will adopt the initiative adoption behavior. At this time, the probability of mandatory adoption by the government can be reduced, and finally it is stable in D3 $(0,1)$, that is, The government does not mandate the adoption of XBRL, and companies adopt XBRL.

When the new XBRL technology first entered the market, most of the companies are in a wait-and-see attitude. The biggest factor affecting the adoption of the company is the economic benefits brought by adopting XBRL technology. When the adoption efficiency is significantly greater than the adoption cost, the enterprise will compete. Imitating the adoption of XBRL technology, and finally achieving satisfactory $(0,1)$, but in reality, the adoption benefits at this time are not clear. When the profit is less than the cost, At this time, if the promotion and adoption of XBRL technology is not very obvious by the company's own will, the government's choice will tend to force enterprises to adopt XBRL technology. According to the arrows in Figure 8, it is easy to see that as the government began to adopt XBRL, the state of adoption of XBRL technology by enterprises and governments became $(1,1)$. Due to the mandatory pressure of adopting XBRL technology brought by government decrees, most companies will choose to adopt XBRL technology in order to avoid high fines and reduce pressure from regulatory authorities with the policy advancement adopted by XBRL, the transparency of accounting information has been improved. After the adoption of the company, the external effects of the society have been continuously expanded, and the government's mandatory adoption costs have also been declining. At this time, the fines for mandatory adoption of XBRL continue to decrease. The government feels that the current adopted enterprises are subject to policy constraints. The social effects of the company's continuous adoption of XBRL have been well formed, and the government's enforcement measures can be cancelled. This is a very the ideal state. 
However, in reality, after the government mandated the adoption of XBRL technology, the expansion and error caused by the immaturity of XBRL technology may reduce the comparability and usefulness, causing certain economic losses and excessively complex compatibility problems for enterprises. When the cost of fines continues to decrease and the government's enforcement measures are not obvious, the company will choose to take actions that are beneficial to its own interests, that is, to abandon the adoption of XBRL technology. Therefore, the government that was originally mandatory will not be forced to adopt. Evolution, and companies will evolve toward a gradual failure to adopt XBRL technology. When the number of non-adopted enterprises increases, the external social benefits are reduced too much, and the government has to re-take the policy measures of mandatory adoption of XBRL technology. At this point, from the initial state, the replication dynamic system will converge to $(1,0)$. From the dynamic interpretation of the replication dynamics, the government departments and enterprises undergo a long-term repeated game. The learning and adjustment strategy is that the enterprise chooses not to adopt XBRL behavior to obtain itself. The biggest benefit, the government will choose to force the adoption of XBRL technology, the government in the process of mandatory adoption of XBRL technology and the supervision of enterprises in the direction of sub-optimal inefficiency, and ultimately in an inefficient state. This is why, under the current favorable conditions that XBRL brings so many advantages, there are very few enterprises that actually integrate XBRL technology into the organization. Therefore, if you want to change this suboptimal or inefficient state of this game, you should quit this suboptimal or inefficient transition path. Only under the premise of the government's correct guidance and market regulation, the evolutionary direction of XBRL technology adoption will exit the inefficiency state of "blocking", realize path substitution, and develop along the path of a virtuous circle.

\section{Conclusion}

Based on the game's bounded rationality, this paper analyzes the decision-making evolution process between enterprise and enterprise, enterprise and government in the process of XBRL technology adoption, and systematically analyzes the government and corporate strategic behavior and its influencing factors. The research results show that under the guidance of the government, the decision to adopt XBRL technology only by the company itself is affected by the probability of adoption by the relevant enterprises and the industry. It takes a while for the new technology to realize its value. Under the guidance of the government, the initial state of XBRL technology adopted by the government and enterprises affects the evolution direction and speed of the system. The evolution of the system has obvious "path dependence" characteristics, the adoption cost of XBRL technology, and the additional benefits brought by adopting XBRL technology. The fine imposed by the government on the mandatory adoption of XBRL affects the adoption of the company. The government's mandatory adoption of 
XBRL costs and the fines charged affect the government's behavioral choices. The external social benefits brought about by adopting XBRL technology have a low impact on the government and enterprises. The development of XBRL technology depends on the government's mandatory implementation of the enterprise.

\section{Policy Recommendations}

In order to promote the long-term development of enterprises and the sustainable development of the social economy, the following policy recommendations are proposed based on the research conclusions. Implement phased guidance policies in different periods. In order to prevent the negative impacts and management challenges caused by inadequate enforcement measures, the government should formulate long-term policy plans and provide corresponding support and supervision based on different periods and stages. For example, adopting open market operations and encouraging investment in the initial stage of adoption. Various methods such as credit policy and tax policy reduce the adoption cost of XBRL technology and help enterprises expand the benefits brought by XBRL technology. In the case of ambiguous returns after adopting XBRL technology, the government should adopt the policy of XBRL technology and maintain certain penalties for not adopting enterprises. In special times, it may even increase penalties.

\section{Acknowledgements}

The paper is supported by Natural Science Foundation of China (71771104): On XBRL domain ontology automatic construction;

\section{Conflicts of Interest}

The authors declare no conflicts of interest regarding the publication of this paper.

\section{References}

[1] Praditya, D., Sulastri, R., Bharosa, N. and Janssen, M. (2016) Exploring XBRL-Based Reporting System: A Conceptual Framework for System Adoption and Implementation. In: Dwivedi, Y.K., Mantymaki, M., Ravishankar, M.N., et al., Eds., Lecture Notes in Computer Science, Springer, Cham, 305-316.

[2] Pinsker, R. and Li, S. (2008) Costs and Benefits of XBRL Adoption: Early Evidence. Communications of the ACM, 51, 47-50. https://doi.org/10.1145/1325555.1325565

[3] Liu, C., Luo, X.R. and Wang, F.L. (2017) An Empirical Investigation on the Impact of XBRL Adoption on Information Asymmetry: Evidence from Europe. Decision Support Systems, 93, 42-50. https://doi.org/10.1016/j.dss.2016.09.004

[4] Chong, D.Z., et al. (2017) The Impact of XBRL on Information Asymmetry: Evidence from Loan Contracting. Journal of Management Analytics, 4, 145-158. https://doi.org/10.1080/23270012.2017.1299047

[5] Makarenko, V. (2017) Modern Innovations in Corporate Reporting. Marketing and 
Management of Innovations, 8, 115-125.

[6] Lai, S.-C., et al. (2015) XBRL Adoption and Cost of Debt. International Journal of Accounting and Information Management, 23, 199-216. https://doi.org/10.1108/IJAIM-04-2014-0031

[7] Santarem Segundo, M. (2015) Analysis of the Presentation of Financial Information to Investors by Publicly Traded Companies. Scire: Representacion y Organizacion del Conocimiento, 21, 53-58.

[8] Cordery, C.J., Fowler, C.J. and Mustafa, K. (2011) A Solution Looking for a Problem: Factors Associated with the Non-Adoption of XBRL. Pacific Accounting Review, 23, 69-88. https://doi.org/10.1108/01140581111130634

[9] Chen, Y.-C. (2012) A Comparative Study of E-Government XBRL Implementations: The potential of Improving Information Transparency and Efficiency. Government Information Quarterly, 29, 553-563. https://doi.org/10.1016/j.giq.2012.05.009

[10] Valentinetti, D. and Rea, M.A. (2013) XBRL for Financial Reporting: Evidence on Italian GAAP versus IFRS. Accounting Perspectives, 12, 237-259. https://doi.org/10.1111/1911-3838.12008

[11] Liu, C.H. et al. (2014) The Impact of XBRL Adoption in PR China. Decision Support Systems, 59, 242-249. https://doi.org/10.1016/j.dss.2013.12.003

[12] Bharosa, N., et al. (2013) Tapping into Existing Information Flows: The Transformation to Compliance by Design in Business-to-Government Information Exchange. Government Information Quarterly, 301, S9-S18.

https://doi.org/10.1016/j.giq.2012.08.006

[13] Dunne, T., et al. (2013) Stakeholder Engagement in Internet Financial Reporting: The Diffusion of XBRL in the UK. British Accounting Review, 45, 167-182. https://doi.org/10.1016/j.bar.2013.06.012

[14] Hoffman, C. and Rodriguez, M.M. (2013) Digitizing Financial Reports-Issues and Insights: A Viewpoint. The International Journal of Digital Accounting Research, 13, 73-98. https://doi.org/10.4192/1577-817/1577-8517-v13_3

[15] Zhao, X.M., Zhang, T.X. and Sun, X.D. (2011) Game Analysis of Financial Information Standard Based on XBRL. Chinese Journal of Management, 8, 273-277.

[16] Wu, Z.S. and Liu, Q. (2015) Market Competition, Government Behavior and XBRL Technology Diffusion. Accounting Research, No. 8, 19-23. 